\title{
Anne Mette Thorhauge from the Department of Media, Cognition and Communication at the University of Copenhagen talks with Kathleen Tyner and Conceição Costa about opportunities and challenges as games are integrated into the formal learning environment.
}

\begin{abstract}
Kathleen Tyner, Conceição Costa - Games for learning connect students' prior experiences and interest in game play with the formal learning environment. First of all, can you discuss the affordances of the concept of "play" in the formal learning environment? Then, please discuss some barriers that make it difficult to integrate game play into the current curriculum.
\end{abstract}

Anne Mette Thorhauge - Play is a key dynamic in learning. From Piaget's historic observations of children's cognitive development to more recent studies in multiple literacies, human's playful tinkering with objects and technology has been emphasised as a crucial aspect of learning. Yet, it is important to be aware that play cannot be 'subverted' to learning. An important aspect of play is its 'auto-telic' nature: we play in order to play. For this reason, we should be careful not to instrumentalise play in formal learning contexts and in this way undermine its nature. We do not play in order to learn, but we sometimes learn in order to reach a desired level of play. For instance, we do not play chess in order to achieve greater strategic skills, but our wish to play chess may inspire us to improve our strategic skills.

KT, CC - Does game genre matter? As developers begin to create games for the formal learning environment, often at affordable prices, what are some of the most essential game design elements that can be used to engage and connect student's formal and informal game experiences? Are some types of games better suited for some disciplines or content areas? Or can most games such as role play games, virtual worlds, puzzle games, adventure games, MMOs, etc. be designed for use with various topics across the curriculum?

AMT - The choice of game genre matters a lot and should represent a key consideration when integrating games in formal learning contexts. While some games require advanced strategic thinking, others call for role-play and negotiation and others again for quick hand-eye coordination. These aspects of games, which are in some cases 
labelled 'game-play', are as important to the learning potential of individual games as the more general themes or content the game may contain (such as 'facts about second world war' or 'basic rules of English grammar'). This does not mean that specific game genre only goes with specific disciplines or contents areas, but it means we will have to be very aware of the type of learning we are hoping to instill, in order to choose the relevant types of games for the purpose.

KT, CC - The gap between academic knowledge and technical skill in every discipline is often difficult to bridge in the elementary and secondary classroom. Games are no exception. Although students are likely to engage with game play in the classroom, fewer students have opportunities to create their own games in the formal school setting. Could you discuss the benefits of gamecreation for learning? What are some barriers to game creation in the classroom? What are some strategies and examples that educators can use to bridge game creation with game play for learning?

AMT - One key benefit of designing games as a way of learning is that it requires you to organise a domain of knowledge in relation to a specific type of game-play and technology. This presupposes a few advanced thinking activities, such as identifying and verifying information, prioritising and presenting information, and reflecting on the implications game-play and technology have for the way it is received by the player. Moreover, building the actual game - however simple - will require the player to tinker with different types of technologies and interfaces in this way enabling a deeper 'inside-out' understanding of the way they work. Finally, gamed design as a process involves a range of organising activities such as coordinating and negotiating tasks within a working group, testing different designs on relevant users, and transforming findings into new and better solutions. These are higher order social and organisational skills that are most definitely relevant in a future digitised society.

However, game design is a rather time-consuming and interdisciplinary process that challenges the conventional organisation of the school-day into lectures and individual disciplines. In this way one key challenge is organisational and involves the reorganisation of classes and classrooms and close collaboration between teachers from different disciplines. Moreover, given that most teachers are rather new to the activity of game-design they will have to learn as they go along. This calls for new pedagogical roles in the classroom. To a lesser extent, teachers will depend on their role as experts in specific knowledge domains and to greater extent they will take on a supportive role to enable creative and experimental processes in the classroom. This also means they should be allowed to make errors and ongoing revisions because this is what happens when you open the curriculum to experimentation and don't know where the process will bring you to begin with. Finally, the open-ended character of game design fundamentally breaks with the way learning is typically managed and measured in a 
wider political system. Any kind of measure comes with a wider political investment and learning measures are no exception. The current focus on quantifiable learning outcomes goes against game design as a way of learning and should be replaced with an approach that focuses more on the processual aspects of learning. This might very well be the greatest challenge of them all for the integration of game-design in the traditional classroom.

KT, CC - In your speech at the Play2learn conference in Lisbon, you proposed that children should select their own resources for learning. From which age do you think they are able to do that? What's the role of the teacher in this process?

AMT - I'm even more radical than this - I think children to a greater extend should be allowed to produce their own learning resources. I take this approach from Sørensen and Levinsen's work on 'students as learning designers' and I believe it holds great potential. As I mentioned earlier on, analysing and representing a knowledge domain requires a range of advanced thinking activities beyond reading and remembering information that other people have already organised for you. Obviously, it will have to include existing resources made by others and one key role of the teacher will be to enable the process by making a range of resources available, initiate activities identifying, verifying, prioritising and presenting information, and not least, frame these activities within a broader learning context where students continuously reflect on their own learning processes.

Kathleen Tyner Associate Professor, The University of Texas at Austin

Conceição Costa Associate Professor, Universidade Lusófona de Humanidades e Tecnologias 